\title{
INFLUENNCIA DO TIPO DE SEMEADURA NA PRODUTIVIDADE DO CONSÓRCIO SORGO - Urochloa brizantha CV MARANDU NO SISTEMA DE INTEGRAÇÃO LAVOURA-PECUÁRIA
}

\author{
CHRYSTIANE MARTINS DE ALMEIDA ${ }^{1}$, ÂNGELA MARIA QUINTÃO LANA², \\ JOSÉ AVELINO SANTOS RODRIGUES ${ }^{3}$, RAMON COSTA ALVARENGA ${ }^{3}$ e IRAN BORGES ${ }^{4}$
}

\author{
${ }^{1}$ Mestre em Zootecnia, UFMG, Belo Horizonte, MG, Brasil, cricalmeida@gmail.com \\ ${ }^{2}$ Professora Associada, UFMG, Belo Horizonte, MG, Brasil, lana@vet.ufmg.br \\ ${ }^{3}$ Pesquisadores, Embrapa Milho e Sorgo, Sete Lagoas, MG, Brasil,avelino@cnpms.embrapa.br, ramon@cnpms.embrapa.br \\ ${ }^{4}$ Professor, UFMG, Belo Horizonte, MG, Brasil,iran@vet.ufmg.br
}

Revista Brasileira de Milho e Sorgo, v.11, n.1, p. 60-68, 2012

\begin{abstract}
RESUMO - O objetivo deste trabalho foi determinar a influência do tipo de semeadura nas variáveis produtivas do consórcio sorgo - Urochloa brizantha. Os tratamentos foram: sorgo consorciado com braquiária na linha e nas entrelinhas de semeadura; sorgo consorciado com braquiária nas entrelinhas de semeadura; sorgo consorciado com braquiária na linha de semeadura; em delineamento em blocos casualizados com cinco repetições A produção de matéria verde da braquiária no consórcio apresentou diferença significativa entre as médias, sendo que a semeadura com a braquiária na linha e nas entrelinhas do sorgo $(31,88)$ e a semeadura com braquiária nas entrelinhas $(27,44)$ foram semelhantes entre si, mas apresentaram diferença em relação ao consórcio do sorgo com braquiária só nas linhas de semeadura $(19,00)$. Já a produção de matéria verde do sorgo não apresentou diferença significativa entre as médias. A produção de matéria seca da braquiária apresentou diferença significativa entre as médias, sendo que a semeadura do sorgo com a braquiária na linha e nas entrelinhas $(7,54)$ foi superior estatisticamente à do sorgo com braquiária nas entrelinhas $(6,17)$ e ao com braquiária na linha de semeadura $(4,43)$. O sistema de plantio que ofereceu maior benefício com maiores valores para produção de matérias verde e seca da braquiária foi o consórcio do sorgo com a braquiária na linha e nas entrelinhas de semeadura.
\end{abstract}

Palavras-chave: integração lavoura-pecuária, Marandu, pastagem, semeadura.

\section{INFLUENCE OF THE TYPE OF SEEDING IN THE PRODUCTIVITY OF THE SORGHUM - Urochloa brizantha cv MARANDU INTERCROPPING IN THE CROP-LIVESTOCK INTEGRATION SYSTEM}

\begin{abstract}
The aim of this work was determine the influence of the type of seeding on productive variables of the sorghum - Urochloa brizantha intercropping. The treatments were: sorghum intercropped with brachiaria in line and inter-lines of sowing, sorghum with brachiaria intercropped inter-rows and, sorghum intercropped with brachiaria in the row. A randomized block design with five replications was used. The sowing of brachiaria in row and inter-rows of sorghum (31.88), and seeding of brachiaria inter-rows (27.44) were similar, but different compared to the intercropping with brachiaria only in sorghum intra-rows (19.00). The production of sorghum green matter did not show significant difference between the means. The dry matter production of brachiaria showed significant difference between the means and the planting of sorghum with brachiaria in row and inter-rows (7.54) was statistically superior to sorghum with brachiaria inter-lines (6.17) and with brachiaria in the row (4.43). Therefore, the planting system that provided the greatest advantage, with highest values of green and dry matter production was the intercropping of sorghum with Brachiaria intra and inter-rows of sowing.
\end{abstract}

Key words: crop livestock integration, Marandu, pasture, sowing.

Versão impressa ISSN 1676-689X / Versão on line ISSN 1980-6477

http://www.abms.org.br 
Tradicionalmente, a agricultura e a pecuária no Brasil mantinham suas atividades produtivas executadas separadamente, ou seja, não ocorriam simultaneamente, havendo quase nenhum sincronismo. Essa prática, ao longo dos anos, contribuiu para acelerar o processo de degradação tanto das áreas de pastagens como de áreas de lavouras, pois não havia a reposição no solo dos nutrientes extraídos pelas pastagens utilizadas na pecuária e na lavoura e a reposição era só parcial, com adubações realizadas na semeadura.

Até o final da década de 60 , a pecuária foi amplamente utilizada por grandes latifundiários para caracterizar a posse da terra. Historicamente, o sistema de produção predominante era extrativista, sobre pastagens nativas, sem preocupação com investimentos e adoção de tecnologia. No entanto, este perfil tem mudado em vista dos altos custos de produção e o produtor rural tem buscado alternativas para sobreviver (Barbosa et al., 2007).

O uso de cultura acompanhante ou companheira na formação de pastagens é uma técnica adotada a partir da década de 70 , principalmente por pequenos e médios produtores e, quando devidamente empregada, pode diminuir o custo do estabelecimento do pasto. Essa técnica de formação de pastagens tem contribuído de forma significativa para a melhoria da qualidade e o aumento da quantidade de forragem produzida e de grãos (Carvalho \& Cruz Filho, 1985; Kluthcouski et al., 1991; Yokoyama et al., 1998). Dentre as espécies mais utilizadas como cultura acompanhante, destaca-se o arroz, o milho e espécies forrageiras perenes, principalmente as dos gêneros Brachiaria, Setaria, Andropogon e Panicum (Evangelista et al., 2002).
Atualmente, essa técnica se destaca como sendo parte das tecnologias sustentáveis e competitivas para alavancar o agronegócio brasileiro. A semeadura de forrageiras para pastejo consorciadas com culturas anuais tem se mostrado uma técnica eficiente e economicamente viável como método de recuperação e renovação de pastagens. Nesse caso, é feita a semeadura simultânea das sementes da cultura anual e da forrageira ou aproveita-se o potencial das sementes de forrageira existente no solo. Após a colheita da cultura, tem-se a pastagem formada (Kichel et al., 1999). Nesse sistema, ainda há o benefício do plantio direto ser mais facilmente viabilizado devido ao condicionamento inicial do solo e à maior oferta de palha pela pastagem para cobertura morta do solo. Com isso, a erosão do solo é minorada, reduzindo-se o assoreamento dos reservatórios e dos cursos d'água (Alvarenga, 2004).

A utilização do sistema de plantio direto (SPD) tem sido crescente, sendo que em 2003, na região dos Cerrados, segundo Duarte et al., (2006), já representava $40,78 \%$ dos sistemas de plantio. Acredita-se que esse percentual já tenha ultrapassado os 65\% em 2008/2009. O grande avanço se deu pelas vantagens comparativas entre o SPD e os sistemas tradicionais em termos agronômicos, econômicos e ambientais. A adoção do SPD em sua plenitude nas diversas condições climáticas e edáficas, no entanto, é altamente dependente de culturas adequadas para a produção e a manutenção de palha sobre o solo, para que o sistema seja eficiente e vantajoso.

Várias culturas têm sido utilizadas e testadas para cobertura de solo, rotação e pastejo no outonoinverno e, entre as mais promissoras, estão o milho, o milheto, o sorgo granífero, o sorgo forrageiro, o nabo forrageiro e as gramíneas forrageiras tropicais, 
consorciadas ou não, sobretudo as braquiárias. A degradação das pastagens, grandes extensões de área com monocultivo da soja no verão, a pressão social sobre a terra, dívidas financeiras, preços de insumos e produtos e competição global vêm exigindo cada vez mais eficiência dos produtores. Nesse sentido, os sistemas de integração lavoura-pecuária (SILPs) podem ser promissores para atender tanto às dificuldades da pecuária, como alternativa de recuperação de pastagens degradadas, como para a agricultura anual e o SPD, visando à produção de palha, à melhoria das propriedades do solo, à utilização plena de equipamentos, a empregos e ao aumento de renda no campo.

Sabe-se que a o plantio consorciado traz inúmeras vantagens ao produtor, ao meio ambiente e à cultura devido às diversas práticas adotadas de adequação ao solo para a recuperação de áreas degradadas, com a melhoria das condições físico-químicas do solo devido à implantação das pastagens e ao aproveitamento dos nutrientes residuais das lavouras na produção de forragem para a estação seca.

O objetivo desde trabalho foi avaliar a influência do tipo de semeadura na produtividade do consórcio sorgo - Urochloa brizantha cv. Marandu.

\section{Material e Métodos}

$\mathrm{O}$ experimento de campo foi conduzido nas dependências do CNPMS (Centro Nacional de Pesquisa de Milho e Sorgo) em Sete Lagoas, MG, a $19^{\circ}$ $27^{\prime} 57^{\prime \prime}$ de latitude Sul e $44^{\circ} 14^{\prime} 48^{\prime \prime}$ de longitude Oeste. O clima é o semi-úmido, a temperatura média anual é de $21^{\circ} \mathrm{C}$, com máxima média anual de $27^{\circ} \mathrm{C}$ e mínima de $15^{\circ} \mathrm{C}$. A precipitação média anual é em torno de $1403 \mathrm{~mm}$. O solo do local é o latossolo vermelho distrófico (Sistema, 1999).
As cultivares utilizadas foram o sorgo BRS 655 e a Urochloa brizantha cv. Marandu. O BRS 655 é um híbrido de porte alto (em torno de 2,5 m), ciclo de 90 a 100 dias (ponto de grãos leitosos/pastosos ideal para ensilagem), possui colmos secos com excelente padrão fermentativo. O capim braquiária é uma gramínea de crescimento entouceirado, ciclo perene e indicada para pastoreio direto. As sementes utilizadas possuíam um VC (valor cultural) de 240 pontos ha-1 para a braquiária e 680 pontos ha-1 para o híbrido de sorgo e foram doadas pelo CNPMS.

Neste estudo, o delineamento foi em blocos casualizados com três grupos experimentais (sorgo plantado com braquiária nas linhas e nas duas entrelinhas de semeadura; sorgo plantado com braquiária somente nas entrelinhas de semeadura; e braquiária semeada imediatamente na linha antes da semeadura do sorgo) e cinco repetições, totalizando 15 unidades experimentais. Cada parcela foi composta por canteiros de $35 \mathrm{~m}^{2}(5 \times 7 \mathrm{~m})$, com área útil para avaliação de respostas de $28 \mathrm{~m}^{2}$ e para a bordadura do sorgo foi considerado um sulco de semeadura em cada lado da parcela, sendo o ensaio experimental conduzido no ano agrícola de 2009/2010.

Foram realizadas amostragens do solo para caracterização físico-química do solo e correções necessárias para o cultivo. O solo foi arado e depois gradeado e toda a área experimental foi sulcada manualmente, com o auxílio de uma enxada, delimitando-se assim os sulcos de semeadura do sorgo e da braquiária. Com base na análise de solo ilustrada na Tabela 1, foi realizada a adubação de base (plantio) com 300 kg de 8-28-16 (NPK) + 0,5\% (Zn) e a adubação de cobertura foi realizada a lanço, com $150 \mathrm{~kg}$ de ureia aos 35 dias após o plantio, ambas de acordo com as recomendações sugeridas pela Comissão de Fertilida- 
de do Solo do Estado de Minas Gerais (Ribeiro et al., 1999).

A semeadura do sorgo convencionalmente é feita nos meses de outubro e novembro, quando se tem coincidiu com a linha de semeadura do sorgo. Após a emergência da espécie consorciada, para o controle de plantas indesejáveis de folhas largas e estreitas foi feita a capina manual.

TABELA 1. Características físico-químicas médias do solo da área experimental ${ }^{1}$ onde foi implantado o consórcio sorgo-Urochloa brizantha cv Marandu.

\begin{tabular}{cccccccccccc}
\hline & $\mathrm{pH}$ & $\mathrm{H}+\mathrm{Al}$ & $\mathrm{Al}$ & $\mathrm{Ca}$ & $\mathrm{Mg}$ & $\mathrm{K}$ & $\mathrm{P}$ & $\mathrm{MO}$ & $\mathrm{SB}$ & $\mathrm{CTC}$ & $\mathrm{V}$ \\
\cline { 2 - 9 } Amostra & & & $\mathrm{cmol}_{\mathrm{c}} \mathrm{dm}^{-3}$ & & & $\mathrm{mg} \mathrm{dm}{ }^{-3}$ & $\mathrm{dag} \mathrm{kg}^{-1}$ & $\mathrm{cmol}_{\mathrm{c}} \mathrm{dm}^{-3}$ & $\%$ \\
\hline $0-20$ & 5,9 & 3,95 & 0,00 & 4,18 & 0,72 & 154 & 26 & 3,15 & 5,29 & 9,24 & 57 \\
\hline
\end{tabular}

${ }^{1}$ Análise do solo realizada no CNPMS.

um grande fotoperíodo, pois o sorgo é uma espécie de dias curtos, em que o menor fotoperíodo induz o florescimento. Esse experimento foi primeiramente plantado no mês de novembro, mas devido a chuvas em excesso, houve perda inicial do material plantado devido à desuniformidade nas parcelas, o que impossibilitou a avaliação pretendida. Então, o replantio foi tardio, realizado no dia 02 de fevereiro. Foi realizada, quando necessária, irrigação por sistema de aspersores no período da manhã para suprir uma possível deficiência hídrica do experimento.

O sorgo BRS 655 foi semeado a uma taxa de $10 \mathrm{~kg} \mathrm{ha}^{-1} \mathrm{e}$ o capim braquiária a $4 \mathrm{~kg} \mathrm{ha}^{-1}$ de sementes puras viáveis, de modo que forneceu 400 pontos de VC. O espaçamento entre as linhas de semeadura do sorgo foi de $70 \mathrm{~cm}$ numa população estimada em 150.000 plantas $\mathrm{ha}^{-1}$. A semeadura foi manual, utilizando-se uma plantadeira tipo planet, que semeia simultaneamente o sorgo e a braquiária. A braquiária foi semeada também manualmente num espaçamento de 23,5 cm nas entrelinhas do consórcio com o sorgo e foi plantada de tal forma que a sua linha de semeadura
O corte do material a ser ensilado ocorreu manualmente no dia 13 de maio (101 dias após o plantio e quando os grãos do sorgo se encontravam no estádio leitoso/pastoso), numa altura de $35 \mathrm{~cm}$ da superfície do solo. Foi cortada toda a parcela experimental e uma amostra de plantas de sorgo e capim braquiária foi cortada e pesada junta para que se obtivesse massa verde do material consorciado, sendo o resultado utilizado para cálculo de produção de matéria verde por hectare. A altura das plantas foi determinada, no momento do corte, através da medida do nível do solo até a extremidade superior da panícula em $20 \%$ das plantas de cada parcela. Outra amostra de plantas da unidade experimental foi tomada, foram separadas as plantas de sorgo das de braquiária, pesadas separadamente para obtenção da massa verde de cada uma no consórcio e levadas ao laboratório para secagem em estufa de circulação forçada a $65^{\circ} \mathrm{C}$ para determinação da massa seca. Também foram analisadas as variáveis de produção do sorgo e da braquiária através da altura das plantas, da população de plantas de sorgo $\left(\mathrm{ha}^{-1}\right)$, da produção 
de massa de matéria verde e da produção de matéria seca.

Foram realizados testes de Lilliefors e Bartlett para verificar normalidade e homocedasticidade dos dados, respectivamente. Foram realizados análise de variância e teste de SNK. Para as análises, foi considerada taxa de erro $(\alpha=5 \%)$ e utilizou-se o programa SAEG 9.1 (UFV, 1997).

\section{Resultados e Discussão}

Os resultados relacionados aos aspectos produtivos do sorgo e do capim Urochloa brizantha $\mathrm{cv}$. Marandu, com população de plantas de sorgo (estande), altura das plantas de sorgo e altura das plantas de braquiária, se encontram na Tabela 2.

A altura das plantas é uma característica que regularmente determina o potencial produtivo de massas seca e verde por hectare (Neumann et al., 2002). Neste trabalho, os valores de altura das plantas de sorgo variaram de 2,10 a 2,18 $\mathrm{m}$, conforme apresentado na Tabela 2. Pode ser observado que o consórcio não influenciou a altura de plantas de sorgo. Todas as alturas de plantas foram muito próximas umas das outras, sendo que na semeadura consorciada a diferença de alturas foi de $0,07 \mathrm{~m}$ da planta em consórcio com a braquiária na linha e nas entrelinhas de semeadura para aquela com a braquiária na entrelinha e somente de 0,01 desta para a planta em consórcio com a braquiária na linha de semeadura.

Molina et al. (2000), avaliando seis genótipos de sorgo, verificaram diferença significativa entre as médias, sendo que a altura das plantas variou de 1,0 a $2,7 \mathrm{~m}$. Oliveira et al. (2005) verificaram variação de 2,12 a 2,74 m, com média de 2,39 m, para os híbridos de sorgo BRS 610 e BR 700 e a variedade BR 506, superando os valores encontrados neste experimento.

Apesar de não haver diferença significativa entre as médias observadas, vale ressaltar que as plantas em geral apresentaram altura menor do que a apresentada normalmente por esse híbrido de sorgo (2,5 m), de acordo com Rodrigues et al., (2008). Esse menor crescimento em relação à altura obtida pelo híbrido pode ser devido à semeadura tardia, quando houve a diminuição do fotoperíodo e a indução do florescimento da planta, afetando assim o seu crescimento.

As alturas obtidas nas parcelas de braquiária variaram de 1,00 a 1,11 m. Da mesma forma que nas alturas das plantas de sorgo, pode-se perceber que as plantas de capim também foram pouco influenciadas pelo consórcio, não havendo diferença significativa entre as médias ( $p>0,05)$. Alencar et al. (2010) encontraram médias de alturas da cultivar Marandu variando de 0,31 a 0,40 m, dependendo da estação do ano e do nível de adubação. Nota-se que os valores apresentados por esses autores foram menores que os encontrados nesta pesquisa; possivelmente, essa diferença seja pelo clima e pelo tipo de solo. Em outros estudos encontrados na literatura, a altura das plantas de Urochloa brizantha cv Marandu foi influenciada pela taxa de semeadura e pelo consórcio, sendo que, quanto maior a taxa de semeadura do milheto utilizado no consórcio, menor a altura das plantas de braquiária, refletindo a competição entre as plantas, o que não ocorreu neste experimento, segundo a análise estatística.

A população de plantas (mil plantas ha ${ }^{-1}$ ) do sorgo nos consórcios encontra-se na Tabela 2. Também nesta variável, não houve diferença significativa $(\mathrm{p}<0,05)$. Então, pode-se sugerir que o tipo de consórcio acaba 
não influenciando a população de plantas. Diferente do que verificaram Borghi \& Crusciol (2007), em que a semeadura adensada do milho proporcionou maior população final de plantas na modalidade de consorciação na entrelinha. Porém, no consórcio do milho com a forrageira na linha, o comportamento foi inverso, ou seja, a braquiária influenciou a população de plantas de milho.

A altura da planta de sorgo apresentou uma correlação positiva e moderada com a altura entre os valores obtidos, sendo que, quando é feita a semeadura do sorgo com braquiária na linha e nas entrelinhas e com braquiária nas entrelinhas, as médias não diferiram estatisticamente entre si, mas diferiram do consórcio quando há semeadura do sorgo com a braquiária na sua linha. Então, o tipo de consórcio influencia na produção de matéria verde do capim braquiária, diferentemente do que constataram Pequeno et al. (2006), em que os arranjos de semeadura do milho não apresentaram diferença

TABELA 2. Parâmetros produtivos da Urochloa brizantha cv Marandu e do sorgo nos plantios consorciados.

\begin{tabular}{|c|c|c|c|c|c|c|c|}
\hline \multirow{3}{*}{ Tratamentos $^{1}$} & \multicolumn{2}{|c|}{$\begin{array}{l}\text { Altura da planta } \\
\text { (m) }\end{array}$} & \multirow{3}{*}{$\begin{array}{l}\text { Número de } \\
\text { plantas de } \\
\text { braquiária* }^{*}\end{array}$} & \multicolumn{4}{|c|}{ Produção de massa $\left(\mathrm{t} \mathrm{ha}^{-1}\right)^{3}$} \\
\hline & \multirow{2}{*}{ Sorgo } & \multirow{2}{*}{ Braquiária } & & \multicolumn{2}{|c|}{ Matéria verde } & \multicolumn{2}{|c|}{ Matéria seca } \\
\hline & & & & Braquiária & Sorgo $^{2}$ & Braquiária & Sorgo $^{3}$ \\
\hline A & 2,10 & 1,01 & 485,60 & $31,88 \mathrm{~A}$ & 46,24 & $7,54 \mathrm{~A}$ & 15,19 \\
\hline B & 2,17 & 1,11 & 426,00 & $27,44 \mathrm{~A}$ & 52,80 & $6,17 \mathrm{~B}$ & 16,84 \\
\hline $\mathrm{C}$ & 2,18 & 1,00 & 506,40 & $19,00 \mathrm{~B}$ & 48,94 & $4,43 \mathrm{C}$ & 16,45 \\
\hline CV $(\%)$ & 5,31 & 16,75 & 11,45 & 12,71 & 10,66 & 12,38 & 11,40 \\
\hline
\end{tabular}

${ }^{1} \mathrm{~A}=$ Sorgo com braquiária na linha e entrelinhas de plantio; $\mathrm{B}=$ Sorgo com braquiária na linha e entrelinhas de plantio; $\mathrm{C}=$ Sorgo com braquiária na linha de plantio; ${ }^{2}$ Médias seguidas de mesma letra na coluna, não diferem significativamente entre si pelo teste de SNK $(\mathrm{p}<0,05)$; "Não significativo.

do capim $(0,53)$ e a população final de plantas de sorgo $(0,51)$. Com isso, pode-se dizer que, à medida que aumenta a altura das plantas de sorgo, também aumenta a altura do capim braquiária e a população final de plantas de sorgo, diferente do que é encontrado na literatura, segundo a qual o consórcio promove uma competição, proporcionando menor altura de plantas de braquiária quando semeadas com sorgo ou milheto.

Quanto à produção de massa verde da braquiária, houve diferença significativa $(\mathrm{p}<0,05)$ significativa sobre a produção de matéria verde.

A produção de massa verde do sorgo não apresentou diferença significativa $(p>0,05)$ entre os tipos de consórcio utilizados. Então, o tipo de semeadura não interfere na produção de matéria verde do sorgo.

Entre as médias obtidas na produção de massa seca da braquiária, houve diferença significativa $(p<0,05)$ entre os tratamentos. O maior valor obtido foi na semeadura de sorgo com braquiária na linha e nas entrelinhas $(7,54 \%)$, sendo este superior 
estatisticamente à semeadura com a braquiária nas entrelinhas $(6,17 \%)$ e com capim semeado somente na linha $(4,43 \%)$. Esse fato pode ser atribuído à presença de uma fileira a mais de plantio da braquiária neste tratamento, o que obviamente aumentaria a sua produção. A diferença entre as produções nos outros dois tipos de consórcio pode ser pelo tipo de semeadura utilizada, sendo que pode ter ocorrido uma competição entre sorgo e braquiária, já que o consórcio onde houve a semeadura de braquiária na mesma linha de sorgo foi o que obteve menor valor. Barnabé et al. (2007) obtiveram valores de produção de matéria seca para o capim de $6,39 \mathrm{tha}^{-1} \mathrm{com}$ o cultivo adubado, valores semelhantes aos obtidos neste experimento. Já Arruda et al. (2008) obtiveram médias de 2,43 $\mathrm{t}$ ha mês $^{-1}$ para o período da seca e $2,45 \mathrm{t}$ ha mês $^{-1}$ para as águas, valores inferiores aos observados no consórcio.

\section{Conclusões}

Apesar da época de semeadura ter sido tardia devido à perda do primeiro material plantado, o consórcio não influenciou a altura das plantas de sorgo e da braquiária e a população final de plantas de sorgo, sugerindo que não há competição entre as espécies consorciadas quando analisadas essas variáveis.

O plantio da braquiária na linha do sorgo pareceu gerar uma competição entre as espécies e, com isso, uma menor produção do capim, o que não ocorreu com as produções de matéria verde e seca do sorgo, sendo esse um fator a ser levado em consideração na hora da escolha do plantio.

O sistema de plantio que ofereceu maior benefício foi o consórcio do sorgo com a braquiária na linha e nas entrelinhas de semeadura, tendo-se obtido com ele maiores valores para produção de matérias verde e seca da braquiária e não havendo diferença significativa para o sorgo.

\section{Agradecimentos}

Ao CNPq (Conselho Nacional de Desenvolvimento Científico e Tecnológico) a concessão da bolsa e ao CNPMS o apoio ao experimento.

\section{Referências}

ALENCAR, C. A. B. de; CÓSER, A. C.; MARTINS, C. E.; OLIVEIRA, R. A. de; CUNHA, F. F. da; FIGUEIREDO, J. L. A. Altura de capins e cobertura do solo sob adubação nitrogenada, irrigação e pastejo nas estações do ano. Acta Scientiarum Agronomy, Maringá, v. 32, n. 1, p. 21-27, 2010.

ALVARENGA, R. C. Integração Lavoura-Pecuária. In: SIMPÓSIO DE PECUÁRIA DE CORTE, 3., 2004, Belo Horizonte, Anais... Belo Horizonte: UFMG, 2004. CD ROM.

ARRUDA, N. V. M. de; ABREU, J.; AMARAL, J. L. do; OLIVEIRA, A. A.; COELHO, F. P.; SANTOS, C. E.; RUEDA, C. T.; FERREGUTTI, B. C.; REZENDE, B. C.; CRUZ, L. B. Produção de matéria seca de capim-braquiarão (Brachiaria brizantha $\mathrm{cv}$. marandu) em lotação rotacionada nos períodos de seca e águas.

Biodiversidade, Rondonopolis, v. 7, n. 1, 2008. Disponivel em: <http://200.129.241.94/index.php/ biodiversidade/article/view/22/19> Acesso em: 15 jan. 2012.

BARBOSA, F. A.; GRAÇA, D. S.; SOUZA, G. M.; Integração Lavoura-Pecuária: Aspectos produtivos na pecuária bovina. 2007. Disponível em: http:// www.agronomia.com.br/conteudo/artigos/artigos_ 
integracao_lavoura_pecuaria_bovina.htm $>$ Acesso em: 23 jul. 2008.

BARNABÉ, M. C.; ROSA, B.; LOPES, E. L.; ROCHA, G. P.; FREITAS, K. R.; PINHEIRO, E. P. Produção e composição químico-bromatológica da Brachiaria brizantha $\mathrm{CV}$. Marandu adubada com dejetos líquidos de suínos. Ciência Animal Brasileira, Goiania, v. 8, n. 3, p. 435-446, 2007.

BEUTLER, A. N.; SILVA, M. L. N.; CURI, N.; FERREIRA, M. M.; PEREIRA FILHO, I. A.; CRUZ, J. C. Agregação de latossolo vermelho distrófico típico relacionada com o manejo na região dos cerrados no estado de Minas Gerais. Revista Brasileira de Ciência do Solo, Viçosa, MG, n. 1, p. 129-136, 2001.

BORGHI, E.; CRUSCIOL, C. A. C. Produtividade de milho, espaçamento e modalidade de consorciação com Brachiaria brizantha em sistema plantio direto. Pesquisa Agropecuária Brasileira, Brasília, DF, v. 42, n. 2, p. 163-171, 2007.

CARVAlHO, M. M.; CRUZ FILHO, A. B. Estabelecimento de pastagens. Coronel Pacheco: EMBRAPA-CNPGL, 1985, 46 p. (EMBRAPACNPGL. Circular técnica, 26).

DUARTE, J. O. ; GARCIA, J. C.; MATTOSO, M. J. Análise da evolução do sistema de plantio direto e sua relação com a evolução da área plantada com sorgo no Cerrado. Sete Lagoas: Embrapa Milho e Sorgo, 2006, 15 p. (Embrapa Milho e Sorgo Documentos, 53).

EVANGELISTA, A. R.; LIMA, J. A. Silagens: do cultivo ao silo. Lavras: UFLA, 2002. 200 p.

KICHEL, A. N.; MIRANDA, C. H.; ZIMMER, A. H. Degradação de pastagens e produção de bovinos de corte com a integração x pecuária. In: SIMPÓSIO DE PRODUÇÃO DE GADO DE CORTE, 1. 1999,
Viçosa, MG. Anais... Viçosa, MG: UFV, 1999. p. 201-234.

KLUTHCOUSKI, J.; PACHECO, A. R.; TEIXEIRA, S. M. OLIVEIRA, E. T. Renovação de pastagens de cerrado com arroz. I. Sistema Barreirão. Goiânia: EMBRAPA-CNPAF, 1991. 19 p. (EMBRAPACNPAF. Documentos, 33).

MOLINA, L. R.; GONÇALVES, L. C.; RODRIGUEZ, N. M.; RODRIGUES, J. A. S.; FERREIRA, J. J.; FERREIRA, V. C. P. Avaliação agronômica de seis híbridos de sorgo (Sorghum bicolor (L.) Moench). Arquivo Brasileiro de Medicina Veterinária e Zootecnia, Belo Horizonte, v. 52, n. 4, p. 385-390, 2000 .

NEUMANN, M.; RESTlE, J.; ALVES FILHO, D. C.; BRONDANI, I. L.; PELLEGRINI, L. G.; FREITAS, A. K. Avaliação do valor nutritivo de planta e da silagem de diferentes híbridos de sorgo (Sorghum bicolor, L. Moench). Revista Brasileira de Zootecnia, Viçosa, MG, v. 31, n. 1, p. 293-301, 2002. Suplemento.

OLIVEIRA, R. P.; FRANÇA, A. F. S.; RODRIGUES FILHO, O.; OLIVEIRA, E. R. de; ROSA, B.; SOARES, T. V.; MELLO, S. Q. S. Características agronômicas de cultivares de sorgo (Sorghum bicolor (L.) Moench) sob três doses de nitrogênio. Pesquisa Agropecuária Tropical, Goiânia, v. 35, n. 1, p. 45-53, 2005.

PEQUENO, D. N. L.; MARTINS, E. P.; AFFERRI, F. S.; FIDELIS, R. R.; SIQUEIRA, F. L. T. Efeito da época de semeadura da Brachiaria brizantha em consórcio com o milho, sobre caracteres agronômicos da cultura anual e da forragem em Gurupi, estado do Tocantins. Amazônia: Ciência \& Desenvolvimento, Belém, v. 2, n. 3, p. 127-134, 2006.

RIBEIRO, A. C.; GUIMARÃES, P. T. G.; ALVAREZ V., V. H. (Ed.). Recomendação para o uso de corretivos 
e fertilizantes em Minas Gerais: 5a. aproximação. Viçosa, MG: Comissão de Fertilidade do Solo do Estado de Minas Gerais, 1999. 359 p.

RODRIGUES, J. A. S.; SANTOS, F. G. dos; SHAFFERT,

R. E.; FERREIRA, A. S.; CASELA, C. R.; TARDIN,

F. D. BRS 655 - Híbrido de sorgo forrageiro para produção de silagem de alta qualidade. Sete Lagoas: Embrapa Milho e Sorgo, 2008. 2 p. (Embrapa Milho e Sorgo. Circular Técnica, n. 107). Disponivel em: $<$ http://ainfo.cnptia.embrapa.br/digital/bitstream/ CNPMS-2009-09/21375/1/Circ_107.pdf> Acesso em: 15 jan. 2012.
SISTEMA brasileiro de classificação de solos. Brasília, DF: Embrapa Produção de Informação; Rio de Janeiro: Embrapa Solos, 1999. 412 p.

UNIVERSIDADE FEDERAL DE VIÇOSA. SAEG

- Sistema de análises estatísticas e genéticas. Versão 7.1. Viçosa, MG, 1997. 150 p. (Manual do usuário).

YOKOYAMA, L. P; KLUTHCOUSKI, J.; OLIVEIRA E.

T. Impactos socioeconômicos da tecnologia "Sistema Barreirão" em Santo Antônio de Goiás. Goiânia: EMBRAPA-CNPAF, 1998. 37 p. (EMBRAPACNPAF. Boletim de Pesquisa, 9). 